Voix et Images

volxetimages

\title{
La bibliothèque religieuse de Jacques Ferron, écrivain et médecin sous la Grande Noirceur (à laquelle il ne croyait pas) et la Révolution tranquille (dont il doutait)
}

\section{Luc Gauvreau}

Volume 41, numéro 3 (123), printemps-été 2016

Destins de l'héritage catholique

URI : https://id.erudit.org/iderudit/1038161ar

DOI : https://doi.org/10.7202/1038161ar

Aller au sommaire du numéro

\section{Éditeur(s)}

Université du Québec à Montréal

\section{ISSN}

0318-9201 (imprimé)

1705-933X (numérique)

Découvrir la revue

Citer cet article

Gauvreau, L. (2016). La bibliothèque religieuse de Jacques Ferron, écrivain et médecin sous la Grande Noirceur (à laquelle il ne croyait pas) et la Révolution tranquille (dont il doutait). Voix et Images, 41(3), 23-46.

https://doi.org/10.7202/1038161ar 


\section{LA B IBLIOTHEQQUE RELIGIEUSE DE JACQUES FERRON, ÉCRIVAIN ET MÉDECIN SOUS LA GRANDE NOIRCEUR (À LAQUELLE IL NE CROYAIT PAS) ET LA RÉVOLTION TRANQUILLE (DONT IL DOUTAIT)}

$+++$

LUC GAUVREAU

Chercheur indépendant

Je vais au lancement de Parti pris. Je m'apparais comme un homme vieilli, sentimental, attaché à des vieilleries, dépassé, mécréant alors qu'autour de moi on est athée ou agnostique ${ }^{1}$.

J'ai lu beaucoup de pieuses chroniques. Quand j'ai été perquisitionné [par de braves gens], durant la nuit qui a suivi l'enlèvement de Pierre Laporte, ma bibliothèque les a édifiés, en particulier le Traité du parfait inférieur qui convenait fort bien à leur état $[\ldots]^{2}$.

L'homme et la femme jouent au bord du ciel./Ils sont joyeux. Hélas !/L'enfant gémit déjà en eux. (La bible amérindienne) ${ }^{3}$

Mécréant déclaré, Jacques Ferron (1921-1985) a pourtant écrit une des œuvres les plus marquées par la culture, l'histoire et l'imaginaire chrétiens de la littérature québécoise du xx siècle. Dans sa lecture du Ciel de Québec, Philippe Haeck avait d'ailleurs proposé de le considérer comme «notre grand écrivain catholique ${ }^{4} »$. Pierre L’Hérault a consacré le dernier chapitre de son Jacques Ferron, cartographe de l'imaginaire au thème du «Salut par l'écriture ${ }^{5}$ ». Récemment, Jacques Cardinal s'est intéressé au récit de l'Incarnation dans Le ciel de Québec ${ }^{6}$, et on peut aussi penser aux études de mythanalyse ou à celle de Gilles Marcotte parlant du "côté village» de Ferron ${ }^{7}$

1 Extrait de son «Journal personnel» (inédit), $1^{\text {er }}$ décembre 1964, Bibliothèque et Archives nationales du Québec, Fonds Jacques-Ferron, 424/030/002.

2 Jacques Ferron, «La descente de la croix selon Albert Camus, auteur de L'étranger», Du fond de mon arrièrecuisine, Montréal, Bibliothèque québécoise, 2015 [1973], p. 122.

3 En exergue au recueil $\mathrm{Du}$ fond de mon arrière-cuisine, p. 13.

4 Philippe Haeck, «La fondation fantastique», Voix et Images, vol. VIII, n 3 , printemps 1983, p. 430. Il ajoute: «Décidément au Québec nous sommes bien originaux et détraqués [...].»

5 Pierre L'Hérault, Jacques Ferron, cartographe de l'imaginaire, Montréal, Presses de l'Université de Montréal, coll. «Lignes québécoises», 1980, p. 219-241.

6 Jacques Cardinal, Le livre des fondations. Incarnation et enquébecquoisement dans Le ciel de Québec de Jacques Ferron, Montréal, XYZ éditeur, coll. «Documents», 2008, 202 p.

7 Gilles Marcotte, « Jacques Ferron, côté village», Études françaises, vol. XII, nºs 3-4, octobre 1976, p. 217-236. 
pour désigner la «familiarité» que l'écrivain avait avec le petit et grand personnel de l'Église. N'importe lequel de ses lecteurs croisera à coup sûr une des figures de l'univers chrétien en lisant une historiette, une lettre ou un de ses romans.

La consultation de la bibliothèque personnelle de Ferron confirme avec force ces jugements et commentaires. On y trouve plus de deux cent soixante-dix ouvrages sur tous les aspects du monde religieux: théologie, rites, institutions, croyances, symbolisme, éloquence, hérésies, histoire, etc. L'ensemble constitue aussi un échantillon significatif d'imprimés religieux: dictionnaires de théologie, monographies de paroisse, œuvres de piété, hagiographies ou vies de personnages pieux, chefsd'œuvre d'éloquence sacrée, sermonnaires, légendaires chrétiens, romans catholiques, mélanges religieux des plus variés... Ce corpus représente environ douze pour cent de cette collection de près de deux mille cinq cents titres. Comment juger de son importance ${ }^{8}$ ? En le comparant au profil de la collection nationale? À la section «religieuse» d'autres bibliothèques personnelles? S'il va de soi que ce corpus forme une partie de l'arrière-plan culturel à partir duquel il a écrit, comment Ferron l'a-t-il utilisé dans ses œuvres? Parfois directement par des citations explicites, souvent par des allusions indirectes. Quelle en serait l'originalité alors que la bibliothèque collective québécoise se sécularisait irréversiblement? Malgré des avis nuancés, l'appartenance de l'œuvre de Ferron à la modernité québécoise n'est pas contestée, du moins pas pour ses œuvres complètes d'écrivain ou de citoyen. Chez un collaborateur de Parti pris, quelque temps membre du Mouvement laïque de langue française (MLLF), cette importante collection d'ouvrages religieux peut étonner. On s'attendrait sans doute à ce que ce corpus soit relativement ancien, mais ce serait oublier que les publications religieuses étaient encore très nombreuses et encore fort lues durant les années où Ferron a constitué sa bibliothèque.

Dans les études sur l'imprimé, la notion d'« ouvrages religieux» renvoie habituellement à un corpus spécialisé, directement lié aux productions des églises, à leurs institutions et aux doctrines officielles. Pour réaliser ce premier inventaire de la bibliothèque religieuse de Ferron, on a retenu une définition plus large, plus près de celle des sciences humaines, qui étudient la religion comme un phénomène humain global. Chez Ferron, les références à cet univers sont si nombreuses et si polymorphes dans leurs manifestations qu'il est difficile d'en établir les contours précis. Ce défi est accentué par le fait que sa bibliothèque est remplie d'ouvrages mineurs d'auteurs peu connus ou anonymes, dont le genre littéraire est mal défini, de livres aux contenus savants ou remplis d'historiettes. Parmi d'autres possibles, un titre représente ce que pouvait être le monde religieux pour Ferron: La Bretagne catholique, description historique et pittoresque, précédée d'une excursion dans le Bocage vendéen. Vie de saints, pèlerinages, légendes, traits historiques, mours, coutumes, anecdotes et paysages, œuvre de Léon-Louis Buron publiée en 1856. Si on ajoute aux deux cent soixante-dix titres de la bibliothèque de Ferron les milliers d'occurrences des huit cents entités religieuses dispersées dans les centaines

8 En comparant le nombre d'ouvrages de sa bibliothèque personnelle aux nombres de titres mentionnés dans son œuvre, on constate que plus de cinq cents titres et neuf cents auteurs mentionnés sont absents de la bibliothèque réelle. 
de textes où elles sont mentionnées ${ }^{9}$, on peut imaginer qu'il soit possible un jour d'écrire une version ferronienne du Québec catholique.

S'il élargit la notion d'imprimé religieux, ce choix bibliographique la restreint aussi pour éviter d'y inclure tous les ouvrages dans lesquels il y a des allusions au monde religieux ou même des influences importantes, comme L'antiphonaire d'Hubert Aquin, Le maître et Marguerite de Mikhaill Boulgakov, Parabole de William Faulkner ou les romans de Laure Conan. Aussi, il est bon de rappeler que ce corpus religieux partageait les rayonnages de sa bibliothèque avec deux ouvrages que Ferron était particulièrement fier de posséder: une édition de l'Encyclopédie, ou Dictionnaire raisonné des sciences, des arts et des métiers de Diderot et d'Alembert en quarante-trois volumes ${ }^{10}$, et les quatre grands in-folio du Dictionnaire historique et critique (1740) de Pierre Bayle, ouvrage emblématique de ce précurseur des Lumières. Placées au centre de la bibliothèque, ces sommes faisaient d'excellents contrepoids aux trois tomes du monument de la casuistique jésuitique: le Dictionnaire des cas de conscience (1741) de Jean Pontas ${ }^{11}$. La mécréance, $c^{\prime}$ est aussi la «mal créance». Et la bibliothèque de Ferron contient autant d'ouvrages pour croire que pour «mal croire»...

Cette bibliothèque religieuse ferait le bonheur d'un esprit anticlérical. Il y trouverait tout ce qu'il faut pour dénoncer «l'opium du peuple ${ }^{12}$ » : l'obscurantisme, les croyances rétrogrades, l'assujettissement des femmes, les sermons culpabilisants et toutes les bondieuseries que l'on veut. Mais il lui manque une section importante pour qu'elle puisse servir aux opposants de l'Église et de la religion: des essais critiques, dénonciateurs de son pouvoir réactionnaire sur la pensée et les individus. Un seul titre l'annonce clairement, l'essai du philosophe Bertrand Russell: Pourquoi je ne suis pas chrétien? Pour nourrir sa critique, Ferron semble s'appuyer davantage sur La pensée sauvage de Claude Lévi-Strauss, Les formes élémentaires de la vie religieuse d'Émile Durkheim et Rabelais et le problème de l'incroyance au Xvie siècle de Lucien Febvre. Pas ou très peu d'œuvres de combat contre l'Église et la religion, et Dieu sait si la bibliothèque des années soixante et soixante-dix est garnie en ce domaine. Aussi, on peut noter l'absence des nombreux ouvrages de "renouveau catholique» suscités par les bouleversements introduits par Vatican II, comme on peut les retrouver chez Fernand Dumont et Jacques Grand'Maison, et dans les revues Cité libre, Relations (des jésuites) ou la Revue dominicaine.

Ferron polémique peu, argumente peu contre la religion. S'il l'a fait, c'est plutôt à travers des lettres aux journaux, sur l'avortement ou l'euthanasie, par exemple. Plutôt: il conte et raconte, emprunte et récrit. Sa bibliothèque ressemble en cela à son œuvre. Elle représente un territoire de fouille, une réserve de sources documentaires

9 Voir la répartition des noms religieux dans l'œuvre de Jacques Ferron, dans le présent article, p. 32.

10 Cet exemplaire se trouve aujourd'hui dans la bibliothèque du Collège Jean-de-Brébeuf, à Montréal.

11 Sauf exception, on consultera la référence complète aux titres mentionnés dans la bibliographie.

12 En 1967, dans une note de son journal, Ferron précise le sens qu'il donne à cette phrase célèbre: "Sur la religion: "l'opium du peuple" de Marx est précédé de la phrase qu'on ne cite pas: "Elle est le soupir de la créature opprimée." Et c'est là qu'elle cesse d'être oppressive, car elle permet l'expression du sentiment d'oppression. Ce qui est beaucoup mieux [que] d'être opprimé en justifiant l'oppresseur, de sentir sans ressentir, comme il arrive dans d'autres religions. Le paradis n'est pas un refuge, mais un modèle, un critère. La justice descend ainsi du ciel sur terre.» 
pour raconter plus que pour condamner. Pour écrire Le ciel de Québec et mettre à quatre pattes, "comme une grosse vache», un cardinal devant le petit Rédempteur Fauché, il est sans doute plus inspirant de lire l'ouvrage de Noël Taillepied, Traité de l'apparition des esprits. A scavoir: des ames separees, fantosmes, prodiges, \& accidens merveilleux, qui precedent quelquefois la mort des grands personnages, ou signifient changement de la chose publique (1616) ou encore La grande bible des noëls anciens, une anthologie établie par le folkloriste Henri Poulaille, qu'un pamphlet anticlérical.

En 1966, l'annonciation de l'envoyé de Papa Boss auprès de la femme élue pour porter son enfant ${ }^{13}$ n'a pas été écrite pour encourager la croyance dans l'Immaculée Conception! Pour la ridiculiser? Difficile de le nier entièrement, mais cela peut cacher une autre intention, celle de la garder dans la mémoire collective, même si c'est dans une forme parodique et carnavalesque. Pour comprendre les paradoxes que contient une bibliothèque de mécréant, ou pour concevoir la position de celui qui est contre la religion à l'intérieur de la religion, les propos de Ferron à Pierre Cantin sur sa participation aux rencontres de la fondation du MLLF sont importants:

[En 1963], on pouvait se rendre compte déjà que l'Église s'effritait et qu'il y avait mauvaise grâce désormais à être anticlérical. La raison pour laquelle je m'étais opposé à [Pierre] Maheu et à [Jacques] Godbout, plutôt sectaires dans ce mouvement, était la suivante: que le catholicisme, plus particulièrement la Contre-Réforme, faisait partie de notre histoire et qu'il faudrait l'enseigner par le dehors, ce qui n'était pas tellement différent que l'enseigner par le dedans ${ }^{14}$.

L'abandon par Ferron de son anticléricalisme militant distingue sa bibliothèque de celle que se constituerait un homme qui combat pour la laïcisation du système scolaire. Bien plus qu'un cabinet de curiosités nourri aux croyances anciennes ou que la collection d'un militant du MLLF, sa bibliothèque de mécréant pourrait être considérée comme un énoncé complexe, hypercomplexe, sur la culture catholique du Canada français et du Québec. Le sens de son choix de lecteur omnivore se révèle à travers les innombrables reprises, détournements, pastiches par lesquels il a soumis sa culture religieuse à sa volonté de la transmettre.

De nombreux livres religieux de Ferron portent des marques de propriété: ex-libris, signatures olographes, dédicaces, annotations, etc. Parce qu'il n'achetait pas ses livres en Europe, ce sont autant de données sur la circulation de la prose catholique au Québec. Ses livres, même les plus anciens, viennent tous ${ }^{15} \mathrm{~d}$ 'ici et montrent leur appartenance à une culture lettrée ou populaire. Les titres, ayant appartenu

13 Comme nous l'apprend l'ébauche d'un chapitre inédit du Ciel de Québec, cet enfant, conçu en 1966 dans Papa Boss, deviendra le jeune Rédempteur qui, en 1937, accroché aux bras de sa mère Marie portant un parachute aux couleurs de l'armée américaine, tombera du ciel sur les terres de Joseph Fauché dans ce roman publié en 1969.

14 [Lettre de Jacques Ferron à Pierre Cantin], 29 septembre 1977 (inédit), Bibliothèque et Archives nationales du Québec, Fonds Jacques-Ferron.

15 En ce sens, les seuls livres «européens» de Ferron sont ceux que lui achète Jean-Marcel Paquette pendant leur longue discussion sur l'influence du jansénisme au Québec, ce qui les situe clairement dans une perspective québécoise sur les imprimés religieux français. On pourra lire ces échanges passionnants dans l'édition de leur correspondance que viennent d'entreprendre Marcel Olscamp et Lucie Joubert. 
un jour à des lecteurs européens, ont traversé l'Atlantique pour répondre d'abord aux demandes d'un autre lecteur du Nouveau Monde, avant de se retrouver dans la bibliothèque d'un écrivain québécois de la deuxième moitié du $\mathrm{xx}^{\mathrm{e}}$ siècle. Pensons à son exemplaire de La vie de $M^{\text {Ile }}$ de Melun (1855), dont la page de faux-titre est illustrée par un magnifique ex-dono olographe que les sœurs de la Providence de Laflèche en France ont donné à monseigneur Ignace Bourget pour célébrer son retour de Rome. Comme le mentionne le libraire Bernard Amtmann dans un catalogue dès mars 1967, ce livre serait mystérieusement sorti de la bibliothèque épiscopale durant les années soixante. Ferron l'acquiert au printemps 1969, comme le confirme un bon $\mathrm{d}^{\prime}$ achat ${ }^{16}$. Sont-ce bien là les documents que le chercheur attendait pour démontrer qu'il a trouvé - enfin! - l'ouvrage dont Ferron s'est inspiré pour écrire ses deux historiettes sur $\mathrm{M}^{\text {lle }}$ de Melun ${ }^{17}$ ? Oui... mais, malheureusement pour lui, pas autant qu'il l'aurait souhaité. Si ces historiettes paraissent dans L'Information médicale et paramédicale en 1974 (soit après l'achat du livre source), de nombreuses références à $\mathrm{M}^{\text {Ile }}$ de Melun et à son époque se trouvent déjà dans une longue série d'historiettes publiées entre 1964 et 1967, reprises ensuite dans le recueil Historiettes (1969), où Ferron pigera largement pour écrire «Anne de Melun I et II» cinq ans plus tard. Une investigation partielle dans les index et les tables des matières de sa bibliothèque, et dans plusieurs ouvrages «religieux» en particulier, permet de trouver des allusions à $\mathrm{M}^{\text {lle }}$ Anne de Melun dans plus d'une vingtaine de titres. La source chez Ferron est toujours plurielle.

Si on ne peut nier l'influence de la bibliothèque personnelle dans l'œuvre d'un écrivain, cet exemple tiré de la bibliothèque religieuse montre comment il peut être difficile de "prouver» le rôle précis d'un livre dans l'écriture d'un texte. D'abord, l'inventaire d'une bibliothèque n'est pas un journal chronologique de milliers d'actes de lecture qui composent la vie de tout lecteur, encore moins d'un aussi grand lecteur que Ferron ${ }^{18}$. Et surtout, son œuvre n'est pas un collage de morceaux choisis, une anthologie de pages extraites de documents, mais la reprise, la trace ou l'écho d'énoncés fragmentaires de textes lus, parcourus ou simplement utilisés comme l'est le vocabulaire de base commun à une époque et à une société. Ferron n'avait pas de Bible chez lui, et pourtant il fait référence à plus de cent quatre-vingts passages de ce Livre des livres. Né en 1921, étudiant chez les jésuites, Ferron avait-il besoin de posséder une Bible pour mentionner Adam et Ėve, les apôtres, le mont Thabor, Marie-Madeleine, Noé, le Cantique des cantiques, la tour de Babel ou comprendre ce que voulait dire la lactation divine de la Sainte Vierge Marie? Comme pour tous les gens de sa génération, la Bible était peut-être moins un livre à posséder qu'un ensemble de références et de discours communs. Et cela même si la Bible catholique

16 Référence à ces documents du Fonds Bernard-Amtmann conservé à Ottawa.

17 Anne de Melun (1619-1679), dite $\mathrm{M}^{\mathrm{ll}}$ de Melun, est une princesse qui consacra toute sa vie au soulagement des malheureux. En1624, elle entre au chapitre de Sainte-Waudru à Mons. En 1649, elle quitte les chanoinesses de Mons et se retire en Anjou où elle fonde un hospice à Baugé. En 1672, elle fonde un hospice à Beaufort, autre petite ville d'Anjou. Elle meurt à Baugé et est inhumée dans l'hôpital qu'elle avait fondé.

18 Mentionnons que les inventaires de bibliothèques d'écrivains comprennent rarement, sinon jamais, les références aux périodiques lus, corpus considérable dans le cas d'un commentateur assidu de l'actualité comme Ferron. 
n'a jamais connu une diffusion aussi grande chez ses fidèles que dans la culture protestante. Ferron avait appris les histoires qui la composent à travers une vaste bibliothèque de textes, tant entendus que lus, de rites, de prières et de cérémonies. Tout cela avait laissé d'innombrables références dans la langue de son temps. Cette Bible absente est le grand livre fantôme de sa bibliothèque; $c^{\prime}$ est pourtant à travers lui qu'elle acquiert son unité, souvent obscure à nos yeux. Avant de mal croire, il vaut mieux avoir été créant-croyant. Cette Bible si souvent citée mais qui reste invisible dans les rayons de sa bibliothèque fait supposer une créance antérieure à sa carrière d'écrivain mécréant, une croyance sans doute enfantine, imposée par l'éducation et, de ce fait même, intégrée à la langue maternelle.

Le corpus religieux de Ferron se répartit à peu près également entre des ouvrages québécois et français, comme toute sa bibliothèque d'ailleurs. Un parcours attentif mène à une évaluation quelque peu différente. Si on y trouve des exceptions, le sujet des titres français porte surtout sur l'histoire de la fille aînée de l'Église tournée vers l'Amérique française. Il y a très peu d'ouvrages sur l'histoire des provinces ou des régions de la France, à l'exception de quelques-uns que l'on peut lier facilement à l'histoire du Québec, comme l'ouvrage de Marie-Joseph Olivier, Un curé breton au $19^{e}$ siècle, vie de $M^{g r}$ Huchet, archiprêtre de la cathédrale de SaintMalo, vicaire général de Rennes (1888). À cette biographie d'un Malouin comme Jacques Cartier, on peut ajouter la Vie de M. Olier, curé de S. Sulpice, à Paris (1818), dont l'importance dans l'histoire de Montréal est considérable. Parfois composées de dizaines de volumes que Ferron n'a probablement que parcourus, les collections de sermons de Jacques-Marie-Louis Montsabré, de Louis Bourdaloue ou de MarieAlbert Janvier sont des exemplaires ayant appartenu à des membres de l'Église d'ici, donc des modèles à suivre et suivis. Le choix sélectif de Ferron dans la bibliothèque française se poursuit même à l'intérieur de certains livres dont il ne retient que les chapitres liés à l'histoire de l'Amérique française. Dans les six imposants volumes de L'histoire des Filles de la Charité de mère Marie-Antoinette, dont l'état est apparemment neuf, on découvre que Ferron a coupé une cinquantaine de pages portant sur les activités de la congrégation en Oregon. De tels exemples se retrouvent aussi dans le corpus québécois, où Ferron pige seulement ce dont il a besoin, laissant tout le reste non lu ni même parcouru. Si un relevé complet de ces pratiques reste à faire, on réalise que la bibliothèque doit être considérée non seulement comme une collection de livres et de documents matériels, mais d'abord comme un ensemble de textes et d'énoncés soumis à différents régimes de lecture: complète ou partielle, continue ou discontinue, souvent fragmentaire, pour répondre aux intentions éditoriales d'un lecteur. Car comment considérer le travail de l'écrivain Ferron sinon comme celui d'un éditeur du lecteur Ferron, un assembleur de fragments d'autres scripteurs produisant un sens nouveau à l'intérieur de sa, de leur prose? Ferron a souvent évoqué son projet de mettre le Québec au centre du monde, parce qu'il était attaché à ce lieu comme l'habitant à sa terre. Alors qu'on imagine l'écrivain au centre de son œuvre, comme l'habitant au centre de sa terre, on constate que le Québec est à la fois ce qui entoure l'œuvre ferronienne et ce qui en constitue le noyau. De même, la bibliothèque d'un écrivain est son environnement intellectuel, elle borde l'œuvre, l'entoure. 
Le recentrement vers son propre milieu que Ferron a effectué sur la bibliothèque française pourrait être interprété comme une lecture régionaliste de la bibliothèque européenne, et critiqué de ce fait. Il lui a néanmoins permis de rappeler qu'en Amérique et au Québec, l'Occident est à l'est! Ce faisant, Ferron a discrètement déplacé Jérusalem, comme ligne de partage entre l'Est et l'Ouest, au milieu du Déluge de l'Atlantique, avant de faire du Saint-Laurent le Jourdain du Nouveau Monde, comme il fera du lac Saint-Pierre les eaux où soufflait le Verbe de Dieu avant la Genèse du comté de Maskinongé racontée par Léon Portanqueue dans L'amélanchier.

Dans «Faiseur de contes», Ferron s'inspire du mythe d'Antée pour illustrer la survie de certains contes français au Québec. Comme le dieu aérien devait toucher terre régulièrement pour reprendre vie, les légendes françaises ont dû être transformées par ce contact avec le Nouveau Monde qui rend leur transmission possible. À sa manière, la bibliothèque de Ferron manifeste cette transplantation ou renaissance de la bibliothèque française au Québec. Pour survivre outre-Atlantique, il faut que les livres français soient intégrés dans les bibliothèques personnelles de lecteurs québécois, relus, cités et repris dans les œuvres québécoises. Parmi bien d'autres, le «repiquage» de Ferron m'a fait consulter L'histoire littéraire du sentiment religieux en France de l'abbé Henri Brémond et Le miroir des âmes, deux œuvres pour le moins inattendues pour quelqu'un de ma génération. Si «piquer, c'est voler», comme le disait un slogan publicitaire, repiquer peut très bien signifier re-voler (ou reprendre) pour un auteur chez qui l'écriture était un exercice d'usurpation. Ce ne sont pas que les contes français que l'on doit repiquer pour qu'ils continuent à vivre en sol québécois, ce sont les bibliothèques réelles nécessaires aux fictions intellectuelles. Repiquer la bibliographie religieuse de Jacques Ferron, c'est la situer dans une bibliographie des bibliothèques personnelles, elles-mêmes intégrées à une bibliologie ${ }^{19}$ des actes de lecture et d'écriture produits à travers les réseaux intertextuels, citationnels et culturels.

Le religieux est un univers sémantique polymorphe. Au-delà de l'identification des sources, est-ce qu'une telle fréquentation des récits religieux a influencé le discours et la prose de Ferron? Ses multiples lectures, sa familiarité avec les genres littéraires propres à ce Grand Récit longtemps commun l'auraient-elles mené à emprunter les codes de la narration catholique pour exprimer sa mécréance? Ferron a rejeté plusieurs fois le concept de prédestination, au cœur, selon lui, du protestantisme anglo-saxon. Cela laisse supposer qu'il y aurait des narrations, supportées par des systèmes rhétorique, discursif et poétique distincts, déterminées par les confessions protestante et catholique. Dans «Les salicaires», le dernier texte de l'Arrièrecuisine, le narrateur a l'impression de s'accuser comme devant un tribunal communiste. Mais l'adoption de ce point de vue narratif peut tout autant venir du rituel de la confession catholique ou même du tribunal de la Grande Inquisition. Sur ce point, Ferron se souvenait-il de ce qu'il avait écrit vers la fin des années quarante:

19 Terme développé par Paul Otlet (1868-1944), bibliothécaire et humaniste belge, concepteur de la classification décimale universelle, dans son Traité de documentation. Le Livre sur le livre, publié en 1934. Un facsimilé de l'édition originale, avec des préfaces de Benoît Peeters, Sylvie Fayet-Scribe et Alex Wright, illustré par François Schuiten, vient de paraître aux éditions Nouvelles Impressions (Bruxelles, coll. «Réflexions faites», 2015, 480 p.). 
«La méchanceté d'un enfant a une cause qui n'est pas en lui. La religion chrétienne est une saleté : elle les habitue à trouver le mal en eux" ? Combien d'exemples peuton trouver dans sa prose pour y étudier les manifestations du Grand Code dont a parlé Northrop Frye ${ }^{20}$, un Grand Code occidentalisé par le déferlement européen sur l'Amérique amérindienne, par la marche triomphante de l'Ancien Monde vers l'Ouest américain?

\section{QUEL AVENIR POUR CETTE BIBLIOTHĖQUE?}

Au moment où l'univers exclusivement composé d'imprimés dans lequel a vécu Ferron semble révolu, sa bibliothèque et celles de bien d'autres de ses contemporains peuvent devenir les lieux d'une investigation renouvelée des échanges culturels. Les outils logiciels et les corpus numérisés offrent des voies d'accès insoupçonnées des chercheurs précédents. Comment vérifier si les vers placés en exergue à $D u$ fond de mon arrière-cuisine sont bien extraits d'une «bible amérindienne» qui n'est mentionnée dans aucun répertoire connu? Ce genre de recherche fut longtemps impossible à effectuer. Aujourd'hui, après quelques investigations sur Google, on trouve une première occurrence de ces vers dans le récit de voyage d'Adolphe-Basile Routhier dans l'Ouest canadien ${ }^{21}$. Mais Ferron ne possédait pas ce titre. Une autre se trouve dans la biographie du père Albert Lacombe ${ }^{22}$ (1827-1916), missionnaire dans l'Ouest canadien, biographie que Ferron possédait. Les deux auteurs mentionnent cependant la même source: Traditions indiennes du Canada Nord-Ouest, une anthologie des légendes amérindiennes compilées par le missionnaire et ethnologue Émile Petitot (1838-1916) ${ }^{23}$ que Ferron ne possédait pas. Le numérique permet ainsi d'ouvrir tous les livres de la bibliothèque simultanément. Il fait entrer le chercheur à l'intérieur du réseau intertextuel intra muros, celui des couvertures des livres et des limites de la description bibliothéconomique traditionnelle. La généralisation de telles investigations rend imaginable (et surtout possible) un système de détection et de traçabilité des énoncés linguistiques. Il faut se demander ce que permettrait une étude comparative exhaustive des œuvres de Ferron, de sa bibliothèque et des corpus numérisés. Inventorier la bibliothèque d'un auteur ${ }^{24}$ (matérielle, intertextuelle et fictive) pour l'intégrer à une bibliothèque de bibliothèques personnelles, en établir le profil

20 Northrop Frye, Le grand Code. La Bible et la littérature, traduit de l'anglais par Catherine Chalier, Paris, Seuil, 1984 [1981], $320 \mathrm{p}$.

21 Adolphe-Basile Routhier, De Québec à Victoria, Québec, Imprimerie de L.-J. Demers \& frère, 1893, p. 256.

22 Geneviève-Elmire Lavallée Olivine, Le père Lacombe: «l'homme au bon cœur». D'après ses mémoires et souvenirs recueillis par une sœur de la Providence, Montréal, Imprimerie du Devoir, 1916, 547 p.

23 Le passage cité, légèrement remanié par les trois auteurs (Routhier, la sœur de la Providence et Ferron), est extrait de "Enna-Guhini (celui qui voit en avant et en arrière)», une légende des «Déné Peaux-de-lièvre». Voir Émile Petitot, Traditions indiennes du Canada Nord-Ouest, Paris, Maisonneuve Frères \& Ch. Leclerc, coll. «Les littératures populaires de toutes les nations», 1886, p. 114.

24 En ce sens, un modèle à suivre serait l'inventaire descriptif de la bibliothèque personnelle (working library) de Marshall McLuhan, acquise par la Thomas Fisher Rare Book Library de l'Université de Toronto, dans lequel on trouve la description de six mille volumes, les marginalia, les marques de propriété, les soulignements et les différents signes d'annotation, ainsi que la liste des artéfacts insérés dans chaque ouvrage. 
culturel pour constituer une bibliologie renouvelée par l'accès à d'importants corpus numérisés, supportée par des outils d'analyse sémantique, d'extraction d'entités nommées et de visualisation de cartes sémantiques de réseaux d'échanges linguistiques, c'est là une perspective stimulante qui exige de repenser les canaux de production et de diffusion de la recherche.

On peut prendre comme une boutade ou une autre formule du polémiste l'affirmation de Ferron selon laquelle il y a une seule Bible à laquelle participent tous les écrivains du monde. Mais comme la Bible est littéralement une bibliothèque, pourquoi s'étonnerait-on que sa bibliothèque personnelle soit l'une de celles qui composent la Bible des bibliothèques québécoises encore à construire et à découvrir?

\section{LA BIBLIOTHĖQUE RELIGIEUSE DE JACQUES FERRON}

Cette bibliographie s'appuie sur l'inventaire numérique réalisé au début des années 2000 par Marie Ferron, fille de l'écrivain, diplômée en bibliothéconomie. On peut consulter cette première version sur le site Jacques Ferron, écrivain ${ }^{25}$. Au fil des ans, j'ai révisé, précisé et augmenté la description de plusieurs ouvrages, surtout les plus anciens. Marie Ferron a aussi conçu un système de cotes de localisation qui permet aujourd'hui de reconstituer l'ordre séquentiel des rayonnages tel qu'on le trouvait dans la maison familiale de Saint-Lambert pendant plus de trente ans. Au moment du déménagement de madame Madeleine Lavallée-Ferron ${ }^{26}$, à la suite des interventions du député Bernard Drainville et du ministère de la Culture du Québec, Bibliothèque et Archives nationales du Québec a entreposé la collection pendant un an. Depuis 2010, le service des archives de la ville de Longueuil conserve la centaine de boîtes et les deux mille cinq cents volumes.

Selon l'inventaire numérique établi par Marie Ferron, la bibliothèque de son père compte deux mille quatre cent soixante-dix-neuf titres. J'ai établi la liste des «sujets» pour proposer un premier classement de cet ensemble d'ouvrages fort divers. Pour ce travail, j'ai retiré les cent quarante et une revues et les soixante-dix œuvres de Ferron; deux mille deux cent soixante-huit livres ont donc été classés.

Ce premier classement de la bibliothèque de Ferron est fondé sur les titres et le nom des auteurs. Il reste approximatif. Un dépouillement plus approfondi permettrait d'en préciser le contenu et de lui ajouter les cotes et mots-clés normalisés des systèmes institutionnels (Dewey et Library of Congress). En cas de doute, les titres ont été inclus dans les catégories «Littérature générale» ou «Histoire générale», c'est pourquoi ces catégories sont quelque peu «gonflées». Plusieurs titres pourraient aussi appartenir à plus d'une catégorie. Malgré ces imprécisions, ce tableau donne un ordre de grandeur relativement juste des principaux domaines du savoir que contient la bibliothèque de Ferron.

25 En ligne: www.ecrivain.net (page consultée le $1^{\text {er }}$ août 2016).

26 Madame Lavallée-Ferron est décédée au début de 2015. 
Avec le soutien de la succession de l'écrivain, la direction du centre culturel Jacques-Ferron, à Longueuil, a entrepris une étude de faisabilité pour mettre en valeur cette collection et l'intégrer à l'institution. Souhaitons que ce projet se réalise et que sa bibliothèque personnelle devienne une bibliothèque publique.

\begin{tabular}{|c|c|}
\hline SUJETS & TITRES \\
\hline Arts (peinture, sculpture, architecture...) & 34 \\
\hline \multicolumn{2}{|l|}{ Histoire } \\
\hline Histoire générale & 34 \\
\hline Histoire américaine (États-Unis, Amérique du Sud) & 31 \\
\hline Histoire britannique (Angleterre, Irlande, Écosse) & 12 \\
\hline Histoire d'autres pays (Chine, Japon, pays d'Afrique...) & 7 \\
\hline $\begin{array}{l}\text { Histoire européenne (en général et d'autres pays que la France et } \\
\text { l'Angleterre) }\end{array}$ & 29 \\
\hline Histoire française & 66 \\
\hline Histoire du Québec et du Canada & 286 \\
\hline Sous-total & 465 \\
\hline \multicolumn{2}{|l|}{ Littérature } \\
\hline Littérature générale (linguistique, critique, histoire littéraire...) & 25 \\
\hline Littérature américaine & 41 \\
\hline Littérature britannique (Angleterre, Irlande, Écosse) & 66 \\
\hline Littérature canadienne-anglaise & 32 \\
\hline Littérature classique gréco-latine & 19 \\
\hline Littérature d'autres pays (Japon, Chine...) & 15 \\
\hline Littérature russe et européenne (Allemagne, Italie...) & 62 \\
\hline Littérature sud-américaine & 15 \\
\hline Sous-total & 275 \\
\hline $\begin{array}{l}\text { Littérature française générale (anthologies, correspondances, } \\
\text { mémoires, œuvres diverses...) }\end{array}$ & 237 \\
\hline - essais & 157 \\
\hline — poésie & 35 \\
\hline - romans & 70 \\
\hline - théâtre & 32 \\
\hline Sous-total & 531 \\
\hline
\end{tabular}




\begin{tabular}{|l|r|}
\hline $\begin{array}{l}\text { Littérature québécoise générale (anthologies, correspondances, } \\
\text { mémoires, œuvres diverses...) }\end{array}$ & 252 \\
\hline - contes & 10 \\
\hline - essais & 102 \\
\hline - poésie & 66 \\
\hline - romans & 132 \\
\hline - théâtre & 6 \\
\hline Sous-total & 568 \\
\hline Sciences humaines & 32 \\
\hline Philosophie & 66 \\
\hline Psychologie, médecine & 157 \\
\hline Religion (doctrines, croyances, histoire religieuse) & 67 \\
\hline Sociologie, anthropologie & 322 \\
\hline Sous-total & 23 \\
\hline Ouvrages de référence (dictionnaires, glossaires, grammaires...) & 50 \\
\hline Divers (botanique, tourisme, géologie...) & 2268 \\
\hline Total & \\
\hline
\end{tabular}

\section{NOMS RELIGIEUX DANS L'EEUVRE DE JACQUES FERRON}

Dans l'index onomastique établi à partir de toute l'œuvre publiée et les correspondances publiées après sa mort, on trouve près de huit cents noms associés au domaine religieux.

\begin{tabular}{|l|c|}
\hline \multicolumn{1}{|c|}{ TYPES DE NOMS } & NOMBRE \\
\hline abbés/curés/chanoines & $39 / 25 / 8$ \\
\hline cardinaux/êvêques/messeigneurs & $14 / 5 / 58$ \\
\hline communautés et ordres religieux & 104 \\
\hline couvents et séminaires/églises & $10 / 14$ \\
\hline Églises (catholique, presbytérienne...) & 9 \\
\hline frères/sœurs & $44 / 75$ \\
\hline noms de la Bible & 180 \\
\hline paroisses & 18 \\
\hline saints/saintes & $69 / 29$ \\
\hline
\end{tabular}




\section{BIBLIOGRAPHIE DES LIVRES RELIGIEUX ET SUR LA RELIGION DE LA BIBLIOTHËQUE PERSONNELLE DE JACQUES FERRON}

\section{THÉOLOGIE， DOCTRINES, RITUELS ET CROYANCES}

+ AUBERT, Roger, Le problème de l'acte de foi. Données traditionnelles et résultats des controverses

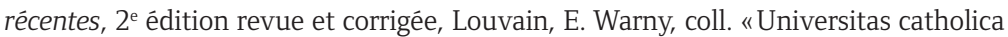
Lovaniensis", 1950, $806 \mathrm{p}$.

+ BARRAL, François (père), La médiation de Marie [Lettre-préface de Monsieur le chanoine Cyrille Gagnon], Québec, Les missionnaires du Sacré-Cœur, 1943, 247 p.

+ BEAUDRY, J[oseph]-U[bald] (honorable), Code de curés, marguilliers et paroissiens, accompagné de notes historiques et critiques, Montréal, La Minerve, 1870, 299 p.

+ BÉGIN, Louis Nazaire (abbé), La primauté et l'infaillibilité des souverains pontifes. Leçons d'histoire données à l'Université Laval, Québec, L. H. Huot éditeur [propriétaire du Canadien], $1873,430 \mathrm{p}$.

+ BERGIER, Nicolas-Sylvestre (abbé), Encyclopédie méthodique: théologie, Paris, Panckoucke, 1788,3 vol.

+ BETTEZ, Norbert Marie, La vie de grâce ou le Paradis sur terre, Montréal, Éditions franciscaines, 1947, $247 \mathrm{p}$.

+ DÉSIRÉ DES PLANCHES (père), L'hymne de la création, préface de Pierre Croidys, avertissement au lecteur par un poète classique, illustrations de Dom Subercaseaux, Pointe-aux-Trembles [Montréal], L'écho de Saint-François, 1946, 187 p.

+ FELLEY, François-Xavier de, Catéchisme philosophique ou Recueil d'observation propre à défendre la religion chrétienne contre ses ennemis, nouvelle édition, Tournay, J. Casterman, 1829, 3 vol.

+ FORTIER, Louis (père), Manuel pratique de vocation, Québec, Brousseau et Desrochers, 1910, $253 \mathrm{p}$

+ GABRIEL DE SAINTE-MARIE-MADELEINE (père), La contemplation "acquise», Paris, Lethielleux, coll. «Bibliothèque du Carmel. Sous le haut patronage du T.R.P. Général des Carmes déchaussés; directeur R.P. Gabriel de Sainte-Marie-Madeleine», 1949, 168 p.

+ GARRIGUET, Louis, Le Bon Dieu. Essai théologique sur l'infinie miséricorde divine, huitième édition, Paris, Librairie Bloud et Gay, 1922, 221 p.

+ GHYVELDE, Frédéric de (père), Vie de N.S. Jésus-Christ, écrite avec les paroles mêmes des quatre évangélistes et enrichie de 33 gravures choisies de Terre sainte, avec leurs légendes explicatives, traduction de l'abbé J.B. Glaire, Québec, Léger Brousseau, 1896, 335 p.

+ GHYVELDE, Frédéric de (père), Le ciel, séjour des élus, Montréal, Revue du Tiers Ordre et de la Terre sainte, 1912, $398 \mathrm{p}$.

+ GIBBONS, James (père), La foi de nos pères ou Exposition complète de la doctrine chrétienne, ouvrage traduit de l'anglais sur la vingt-huitième édition avec l'autorisation spéciale de l'auteur par l'abbé Adolphe Saurel, Montréal, Beauchemin, coll. «Bibliothèque canadienne. Collection Maisonneuve», 1925, 208 p.

+ GIRAUD, Sylvain Marie (père), De l'esprit et de la vie de sacrifice dans l'état religieux, huitième édition, Paris, Delhomme et Briguet éditeurs, 1889, 556 p.

+ HAEGY, Joseph-Antoine (père), Manuel de liturgie et cérémonial selon le rite romain, Paris, J. Gabalda, 1923, 623 p. 
+ HAUSHERR, Irénée, Les leçons d'un contemplatif. Le traité de l'oraison d'Evagre le Pontique, Paris, Beauchesne et fils, 1960, 197 p.

+ HERVÉ-BAZIN, Ferdinand-Jacques, Le jeune homme chrétien, sixième édition, Paris, Victor Lecoffre, 1906, $271 \mathrm{p}$.

+ [S. a.], Instruction familière sur le jansénisme de la prédestination et de la grâce par demandes et réponses, Liège, Guillaume Henry Streel, 1711, 362 p.

+ [S. a.], Instructions chrétiennes sur les huit béatitudes par demandes et réponses, Paris, Wille, 1732, $402 \mathrm{p}$.

+ JAQUES, Jaques, Le faut mourir et les excuses inutiles qu'on apporte à cette necessité. Augmenté de l'Avocat nouvellement marié, \& des pensées sur l'éternité. Le tout en vers burlesques, Lyon, Jacques Canier, 1684, 502 p.

+ LE COURTIER, F[rançois] J[oseph] ( $\left.\mathrm{M}^{\mathrm{gr}}\right)$, Manuel de la messe ou Explication des prières et des cérémonies du saint sacrifice, Paris, Librairie d'Adrien Le Clère et $C^{\mathrm{ie}}$, 1854, 496 p.

+ [S. a.], Le livre des professes, Montréal, Librairie Saint-Joseph, 1879, 603 p.

+ [S. a.], Le miroir des âmes, Beauceville, Imprimerie de l'Éclaireur, 1924, 131 p.

+ LEBLANC, Thomas, Le saint travail des mains ou la manière de gagner le ciel, troisième édition, Avignon, Séguin aîné, 1846, 5 vol.

+ LEFEBVRE, Al[exis], De la folie en matière de religion, Paris, Putois-Cretté, 1866, 455 p.

+ LEMOINE, Albert, L'âme et le corps, études de philosophie morale et naturelle, Paris, Didier et $C^{i e}$, $1862,423 \mathrm{p}$.

+ LIBERCIER, Marie-Albert (père), L'éducation des filles par les religieuses enseignantes. Instructions, avis, conseils d'après $M^{\text {me }}$ de Maintenon, Paris, Téqui, 1902, 268 p.

+ MAILlOUX, Alexis, Le manuel des parents chrétiens, Montréal, VLB éditeur, 1977, 328 p.

+ MARTIN, Félix, Manuel du pèlerin de Notre-Dame-du-Bon-Secours à Montréal, Montréal, Lovell et Gibson, 1848, 178 p.

+ [S. a.], Nouvelles ecclésiastiques ou Mémoires pour servir à l'histoire de la constitution Unigenitus. Suite des Nouvelles ecclésiastiques, Paris, [s. é.], 1728, [s. p.].

+ PELLETAN, Eugène, Profession de foi du $19^{e}$ siècle, cinquième édition, Paris, Pagnerre libraireéditeur, 1864, $400 \mathrm{p}$.

+ PERCHAPPE, M., Recherches historiques et critiques sur la démonologie et la sorcellerie au $X V^{e}$ siècle, le maillet des sorcières, Rouen, A. Peron, 1843, 37 p.

+ PERRODIL, Victor de, Dictionnaire des hérésies, des erreurs et des schismes ou Mémoires pour servir à l'histoire des égarements de l'esprit humain par rapport à la religion chrétienne, nouvelle édition corrigée et augmentée, Paris, Royer, 1845, 2 vol.

+ PONTAS, Jean, Dictionnaire de cas de conscience ou Décisions, par ordre alphabétique, des plus considérables difficultés touchant la morale et la discipline ecclésiastique. Tirées de l'Écriture, des conciles, des décrétales des papes, des pères et des plus célèbres théologiens et canonistes tant anciens que modernes..., nouvelle édition, Paris, G. F. Quillau, 1741, 3 vol.

+ REB, L. et Louis SCHAUER DE MARCKOLSHEIM, Le code moral et religieux de l'officier, du sousofficier et du soldat, Paris, Leautey, 1852, 261 p.

+ RINGUET, Jean, La vie de foi, Paris, Lethielleux, 1931, 366 p.

+ SAINT-AMABLE, Rogier Modeste de, Le parfait inférieur ou l'Art d'obéir, t. II, nouvelle édition, Paris, Librairie Jacques Lecoffre, 1868, 311 p.

+ SAUSSERET, Paul, Apparitions et révélations de la très sainte Vierge depuis l'origine du christianisme jusqu'à nos jours, Paris, Louis Vives, 1854, 2 vol. 
+ SERTILlANGES, Antonin-Dalmace, Prières et musiques, Paris, Spes, 1938, 88 p.

+ SCHOUPPER, François Xavier (père), Cours abrégé de religion ou Vérité et beauté de la religion chrétienne. Manuel approprié aux établissements d'instruction. Apologétique, dogmatique et morale, Bruxelles, Société belge de librairie, 1899, 493 p.

+ TAILLEPIED, N[ö̈l], Traité de l'apparition des esprits. A scavoir: des ames separees, fantosmes, prodiges, \& accidens merveilleux, qui precedent quelquefois la mort des grands personnages, ou signifient changement de la chose publique, Paris, Jean Corrozet, 1616, 227 p.

+ THIVOLliER, P[ierre], Le libérateur. Vie de Jésus-Christ, Issy-les-Moulineaux, Missions ouvrières paroissiales, 1948, $349 \mathrm{p}$.

+ UN RELIGIEUX CHARTREUX, La vie contemplative, son rôle apostolique, [s. v.], Imprimerie de Parkminster, 1928, $142 \mathrm{p}$.

+ [S. a.], Vers une spiritualité de l'action. Notes de retraite selon l'enseignement du R.P. Drujon, S.J., aumônier général de la J.É.C. de France, rédigées avec soin par les révérendes Sours de SainteCroix, Lachine, Imprimerie Sainte-Anne, 1946, 148 p.

+ WINOWSKA, Maria, La vierge de la révélation, Paris, Arthème Fayard, 1957, 188 p.

\section{II. ÉLOQUENCE SACRÉE, ÉCRITS SPIRITUELS ET SERMONS}

+ BLAMPIGNON, M. [Émile], Étude sur Bourdaloue avec quelques documents inédits, suivie d'un choix de sermons, Lille, Société Saint-Augustin, 1886, 396 p.

+ [BOILEAU, Charles], Panégyriques choisis de feu monsieur l'abbé Boileau, prédicateur ordinaire du Roy, et l'un des Quarante de l'Académie Françoise, Paris, André Cailleau, 1719, 456 p.

+ BOSSUET, Jacques Benigne, Recueil des oraisons funèbres, nouvelle édition revue et augmentée, Paris, chez la veuve Nyon, 1803, 624 p.

+ BOSSUET, Jacques Bénigne, Sermon sur la mort, Paris, Éditions d'art Édouard Pelletais, 1921, 80 p.

+ BOURDALOUE, Louis, Sermons sur l'impureté, sur la conversion de Madeleine et sur le retardement de la pénitence, Paris, Éditions Brossard, 1921, 202 p.

+ CROISET, Jean, Retraite spirituelle pour un jour de chaque mois, nouvelle édition, t. II, Paris, Edné Couterot, 1712, 384 p.

+ FÉNÉLON, François de Salignac de La Mothe, Écrits spirituels, Lausanne, Guilde du Livre, 1951, $255 \mathrm{p}$.

+ FLÉCHIER, Esprit, Recueil des oraisons funèbres prononcées par Messire Esprit Fléchier, évêques de Nîmes. Nouvelle édition, dans laquelle on a ajouté un Précis de la vie de l'auteur, Rouen, de l'Imprimerie privilégiée, 1790, 248 p.

+ JANVIER, Marie-Albert, Exposition de la morale catholique. Conférences de Notre-Dame de Paris, Paris, Lethielleux, 1903, 13 vol.

+ JANVIER, Marie-Albert, Conférences de Notre-Dame de Paris. Exposition de la morale catholique: morale spéciale, Paris, Lethielleux, 1916-1924, 9 vol.

+ [S. a.], Les fioretti de saint François, Paris, Club du meilleur livre, 1957, 387 p.

+ [S. a.], Livre de prières du jeune chrétien, Montréal, Frères des écoles chrétiennes, [s. d.], 512 p.

+ MARMiON, Colomba D., Le Christ, vie de l'âme. Conférences spirituelles, Namur/Paris, Abbaye de Maredsous/Desclée de Brouwer et Cie, 1949, 525 p.

+ MARMiON, Colomba D., Le Christ dans Ses mystères. Conférences spirituelles, Namur/Paris, Abbaye de Maredsous/Desclée de Brouwer et $C^{\mathrm{ie}}, 1957,446 \mathrm{p}$.

+ MONTSABRÉ, J[acques-]M[arie-]L[ouis], Conférences de Notre-Dame de Paris. Exposition du dogme catholique, Paris, Lethielleux, 1903, 31 vol. 
+ OLIER, Jean-Jacques, Lettres spirituelles, Paris, Gallimard, 1851, 2 vol.

+ THÉRĖSE D'AVILA (sainte), Le chemin de la perfection, traduit de l'espagnol par les carmélites du premier monastère de Paris, Montréal, Fides, coll. «Les maîtres de la spiritualité. Collection dirigée par les religieux du Carmel de Nicolet», 1958, 268 p.

\section{I I . H I S T O I R E}

+ BAUNARD, Louis $\left(\mathrm{M}^{\mathrm{gr}}\right)$, Autour de l'histoire, scènes et récits, Paris, Librairie Charles Poussielgue, 1898, $376 \mathrm{p}$.

+ BAUNARD, Louis ( $\mathrm{M}^{\mathrm{gr}}$ ), Le collège chrétien, Paris, J. de Gigord, 1924, 2 vol.

+ BEAUREPAIRE, Charles, Essai sur l'asile religieux dans l'empire romain et la monarchie française, Paris, Durant libraire, 1854, 84 p.

+ BIRON, Hervé, Grandeurs et misères de l'église trifluvienne, 1617-1947, Trois-Rivières, Éditions Trifluviennes, 1947, $242 \mathrm{p}$.

+ BOLOGNA, Giacinto da, La pratique missionnaire des pp. capucins italiens dans les royaumes de Congo, Angola et contrées adjacentes; brièvement exposée pour éclairer et guider les missionnaires destinés à ces saintes missions, Paris/Louvain, Spes/Laucam, 1931, 118 p.

+ BRÉMOND, Henri, L'évolution du clergé anglican, Paris, Bloud et $C^{\mathrm{ie}}$, coll. «Science et religion. Études pour le temps présent», 1906, 63 p.

+ BURON, Léon-Louis, La Bretagne catholique, description historique et pittoresque. Précédé d'une excursion dans le bocage vendéen. Vie de saints, pèlerinages, légendes, traits historiques, mœurs, coutumes, anecdotes et paysages, Paris, Périsse et frères, 1856, 457 p.

+ CARRACCIOLI, Antoine, De la vie du pape Clément XIV, troisième édition revue, corrigée et augmentée, Paris, chez la veuve Desaint, 1776, 501 p.

+ CHARLEVOIX, Pierre François Xavier, Histoire du christianisme au Japon, nouvelle édition, Paris, Librairie ecclésiastique du Rusand, 1828, 2 vol.

+ CLARK, Charles Lyton, Voyageurs, robes noires et coureurs des bois. Stories from the french exploration of North America, selected and edited by Charles Lyton Clark, New York, Columbia University Press, 1934, 391 p.

+ CORBETT, William, Lettres sur l'histoire de la Réforme en Angleterre et en Irlande, Paris, Gaume et frères, 1827, 2 vol.

+ COYNART, Charles, Une sorcière au XviII siècle. Marianne de la ville, Paris, Hachette, 1902, 286 p.

+ CRÉTINEAU-JOLY, Jacques, Clément XIV et les Jésuites ou Histoire de la destruction des Jésuites, $3^{\mathrm{e}}$ édition, Paris, Mellier et frères, 1848, 437 p.

+ D'AUBARE, Gabriel de, La révolution des saints, 1520-1536, deuxième édition, Paris, Gallimard, 1946, $200 \mathrm{p}$.

+ DANIEL-ROPS, Jésus et son temps, Paris, Fayard, 1948, 634 p.

+ DANIEL-ROPS, L'Église des temps classiques, t. I: Le grand siècle des âmes, Paris, Arthème Fayard, 1958, $495 \mathrm{p}$.

+ DANIEL-ROPS, L'ère des grands craquements, Paris, Arthème Fayard, 1958, 538 p.

+ DAVY, Marie-Madeleine, Théologie et mystique de Guillaume de Saint-Thierry. La connaissance de Dieu, Paris, Librairie philosophique Vrin, coll. «Études de théologie et d'histoire de la spiritualité», 1954, 341 p.

+ DE VAULX, Bernard, Histoire des missions catholiques françaises, Paris, Arthème Fayard, 1951, $552 \mathrm{p}$.

+ DEFRANCE, Eugène, Singularité religieuse, Paris, Noël et Chalvon, 1907, 100 p. 
+ DelaPlanche (abbé), Pèlerin de Terre sainte. Voyage en Égypte, en Palestine, en Syrie, à Smyrne et à Constantinople, Québec, N. S. Hardy, 1887, 471 p.

+ DIONNE, N[arcisse]-E[uthrope], Les ecclésiastiques et les royalistes français réfugiés au Canada à l'époque de la Révolution, 1791-1802, Québec, [s. é.], 1905, 443 p.

+ DUPUY, Paul, Villemarie, petites fleurs religieuses du vieux Montréal, Montréal, Librairie SaintJoseph, Cadieux et Derome, coll. «Bibliothèque religieuse et nationale», 1885, 216 p.

+ FAILLON, Étienne-Michel, Mémoires particuliers pour servir à l'histoire de l'Église de l'Amérique du Nord, t. II, Paris, Périsse et frères, 1853, 519 p.

+ FEBVRE, Lucien, Le problème de l'íncroyance au 16 siècle. La religion de Rabelais, Paris, Albin Michel, 1962, 544 p.

+ FERLAND, J[ean]-B[aptiste]-A[ntoine], Observations sur un ouvrage intitulé Histoire du Canada par M. l'abbé Brasseur de Boubourg, Paris, Charles Bouniol, 1854, 94 p.

+ FRANCE, Anatole, L'Église et la république, Paris, Jean-Jacques Pauvert, 1964, 207 p.

+ GOYAU, Georges, Les origines religieuses du Canada, Paris, Grasset, 1924, 285 p.

+ GRAVEL, Albert, Aux sources de notre histoire religieuse dans les Cantons-de-l'Est, Sherbrooke, Apostolat de la presse, 1952, $149 \mathrm{p}$.

+ GRENTE, Georges $\left(\mathrm{M}^{\mathrm{g}} \mathrm{r}\right)$, Le beau voyage des cardinaux français aux États-Unis et au Canada, Paris, Plon, 1927, 338 p.

+ GUÉRIN, Marcel, Le gouvernement des missions, Québec, Faculté de droit canonique de l'Université Laval, 1944, 253 p.

+ GUILlEMin, Henri, La bataille de Dieu, Montréal, Éditions du milieu du monde, 1946, 246 p.

+ HUGUET, J[ean]-J[oseph], Les victoire de Pie IX sur les garibaldiens en 1867, [s. v.], Librairie catholique de Périsse et frères, 1868, 396 p.

+ HUGUET, J[ean]-J[oseph], Terribles châtiments des révolutionnaires ennemis de l'Église depuis 1789 jusqu'en 1870, 2e édition, Paris, Nouvelle maison Périsse et frères, 1870, 548 p.

+ JÉHAN, L[ouis] F[rançois], La cité du mal ou Les corrupteurs du siècle, Paris, Ambroise Bray, $1859,436 \mathrm{p}$.

+ JOUVE, Odoric Marie, Un franciscain et le Canada, t. I: L'établissement de la foi, 1615-1629, Québec, Couvent des SS Stigmates, 1915, 506 p.

+ JOYAL, Arthur, Excursion sacerdotale chez les têtes de boule, Québec, la Cie d'imprimerie commerciale, 1915, $87 \mathrm{p}$.

+ LEFAIVRE, Albert, La France canadienne, la question religieuse, les races française et anglosaxonne, Montréal, Réédition Québec, 1969, 45 p.

+ LENEUF, H., La foi irlandaise en Amérique, souvenirs d'un missionnaire, Citaux, Imprimerie et librairie Saint-Joseph, 1880, 284 p.

+ LÉON XI (pape), Lettres du cardinal de Florence sur Henry IV et la France, 1596-1598. Documents inédits des Archives vaticanes recueillis et présentés, Paris, Grasset, 1955, 250 p.

+ [S. a.], Maskinongé. Lettres de deux prêtres, d'un avocat, d'un notaire et d'une nonne, et les réponses à ces lettres par des missionnaires protestants, Montréal, Société missionnaire de la mission de Grande-Ligne, 1892, 134 p.

+ [S. a.], Montréal aux premiers jours. Pages des Relations des jésuites, 1637-1672, préface de Léon Pouliot, Montréal, Société Saint-Jean-Baptiste, 1942, 178 p.

+ PICOT, Michel Pierre Joseph, Mémoires pour servir à l'histoire ecclésiastique pendant le XVIII $I^{e}$ siècle, seconde édition considérablement augmentée, Paris, Imprimerie Adrien Le Clère, 1815,4 vol. 
+ [S. a.], Premier congrès de tempérance de Montréal, tenu à Ville Saint-Pierre le 25 octobre 1909, procès verbal et travaux, Montréal, Imprimerie des sourds et muets, 1909, $139 \mathrm{p}$.

+ RAVIER, M. Pierre (abbé), La clef du trésor de l'Église ou les Indulgences expliquées aux fidèles, ouvrage dogmatique et pratique, Paris, Gaume et frères, 1851, 500 p.

+ ROY, Charles, Visite de S. E. M ${ }^{g r}$ Stagni dans les Cantons-de-l'Est, du 4 au 10 octobre 1913, Montréal, Laflamme et Proulx, 1914, 235 p.

+ ROY, Raoul, Les églises vont-elles disparaître? Dossier de la lutte pour sauver de la démolition l'église, la chapelle et le presbytère de la paroisse Sainte-Catherine-d'Alexandrie à Montréal, Montréal, Édition du Franc-Canada, 1976, 170 p.

+ RUSSELL-KILlOUGH, Frank, Dix années au service pontifical. Récits et souvenirs, Paris, Victor Palmé, 1971, 485 p.

+ RUYSSEN, R[enée] P[osteaux], France religieuse du XII au Xv siècle, Paris, Casterman, 1958, $315 \mathrm{p}$.

+ SUTTER, Paul, Le diable, ses paroles, son action dans Les possédés d'Ilfurt, deuxième édition, Paris, Arthur Savaete, 1921, 125 p.

+ THÉRIAUlT, Yvon, L'apostolat missionnaire en Mauricie, Trois-Rivières, Éditions du Bien public, 1951, $141 \mathrm{p}$.

+ TRUDEL, Marcel, L'Église canadienne sous le régime militaire, 1759-1764, t. II: Les institutions, Québec, Presses de l’Université Laval, 1957, 490 p.

\section{V. B I OGR A P H IES ET HAGIOGRAPH IES}

+ ABELLY, Louis, Vie de saint Vincent de Paul, instituteur et premier supérieur de la congrégation de la mission et des Filles de la charité, Clermond-Ferrand, Thibaud-Landriot imprimeur-éditeur, 1835,3 vol.

+ ALAIN, P., Une fleur dieppoise. Berthe Lefebvre, sœur Marie Colomban (1883-1925), Blois, Éditions de la maison Saint-Antoine, 1932, 226 p.

+ [S. a.], Annette ou La messe mystique. Biographie d'Annette Bernard, de Saint-Jude, SaintHyacinthe, province de Québec, 1912-1932, préface du père M.-J. Benoit, Montréal, Beauchemin, 1946, $158 \mathrm{p}$.

+ [S. a.], Apothéose de $M^{g r}$ Louis François Laflèche, préface de François-Xavier Cloutier, TroisRivières, Imprimerie Saint-Joseph, 1926, 226 p.

+ AUCLAIR, Élie J[oseph], Vie de mère Caron, l'une des sept fondatrices et la deuxième supérieure des Sœurs de la charité de la Providence, 1808-1888, Montréal, [s. é.], 1908, 271 p.

+ AUCLAIR, Élie J[oseph], Vie de mère Catherine Aurélie, Saint-Hyacinthe, Monastère du Précieux-Sang, 1923, 448 p.

+ BÉRUBÉ, Paul Henri, Une pierre d'angle: mère Zita de Jésus, fondatrice des servantes de Jésus Marie, 1865-1903, Ottawa, Éditions de l'Université d'Ottawa, 1945, 309 p.

+ [S. a.], Biographie de Frs. Vezina, caissier de la Banque nationale, Québec, Typographie C. Darveau, 1876, $76 \mathrm{p}$.

+ BOIS, Louis-Édouard, M. Jean Raimbault, archiprêtre, curé de Nicolet, Québec, Imprimé par Auguste Côte, 1872, 110 p.

+ BROGLIE, Emmanuel de, Saint Vincent de Paul, Paris, J. Gabalda, 1918, 234 p.

+ CATTA, Étienne, Le très révérend père Basile Antoine Moreau et les origines de la congrégation de Sainte-Croix, Montréal, Fides, 1950, 723 p.

+ CHARRON, Yvon, Mère Bourgeois, Beauchemin, Montréal, 1950, 249 p. 
+ CHESTERTON, Gilbert Keith, Saint Thomas d'Aquin, version française par Maximilien Vox, préface du $\mathrm{M}^{\mathrm{gr}}$ p. Gillet, Paris, Plon, [s. d.], 217 p.

+ COGNET, Louis, Saint Vincent de Paul, Bruges, Desclée de Brouwer, 1959, 247 p.

+ CROIDYS, Pierre, Frère André de la congrégation de Sainte-Croix, le prodigieux apôtre canadien de Saint-Joseph, Paris, Éditions du Vieux-Colombier, 1957, 117 p.

+ DAVID, L[aurent]-O[livier], Monseigneur Paul Bruchési, Montréal, Beauchemin, 1926, 95 p.

+ DIONNE, N[arcisse]-E[uthrope], Vie de C. F. Painchaud, Québec, Léger Brousseau, 1814, 435 p.

+ DIONNE, N[arcisse]-E[uthrope], Monseigneur de Forbin Janson, évêque de Nancy et de Toul, primat de Lorraine, etc. Sa vie, son œuvre en Canada, Québec, Léger Brousseau, 1895, 196 p.

+ DODIN, André, Saint Vincent de Paul et la charité, Paris, Éditions du Seuil, coll. «Maîtres spirituels", 1960, $192 \mathrm{p}$.

+ DOMMANGET, Maurice, Le curé Meslier, athée, communiste et révolutionnaire sous Louis XIV, Paris, Julliard, coll. «Dossier des Lettres nouvelles», 1965, 552 p.

+ DRAGON, Antonio, Pour le Christ Roi, Miguel Augustin Pro, Montréal, Imprimerie du Messager, 1929, $189 \mathrm{p}$.

+ DUCHAUSSOIS, P[ierre], Rose du Canada. Mère Marie Rose, fondatrice de la congrégation des soeurs des Saints-Noms-de-Jésus-et-de-Marie, Montréal, Granger et frères, 1932, 347 p.

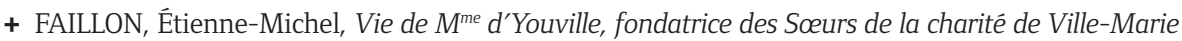
dans lî́le de Montréal en Canada, Villemarie [Montréal], chez les Sœurs de la charité, 1852, 491 p.

+ FAILLON, Étienne-Michel, L'héroïne chrétienne du Canada ou $M^{\text {lle }}$ de Ber, Montréal, chez les sœurs de la congrégation Notre-Dame, 1860, 404 p.

+ [S. a.], Fleurs ursuliennes. Notices biographiques d'anciennes élèves des Ursulines des TroisRivières, Trois-Rivières, [s. é.], 1906, 377 p.

+ GOSSELIN, Auguste, Henri de Bernières, premier curé de Québec, Québec, Dussault et Proulx imprimeurs, 1902, $392 \mathrm{p}$.

+ GOYER, Francis, Un sauveur au XX siècle ou apôtres modernes. Causeries données à l'Heure dominicale de Radio-Canada, Québec, Secrétariat des œuvres eucharistiques, 1944, 131 p.

+ GUÉRARD, J. M., Vie du bienheureux Grignion de Montfort, Rennes, Hyacinthe Callière libraireéditeur, 1887, $580 \mathrm{p}$.

+ GUILLERMOU, Alain, Saint Ignace de Loyola et la compagnie de Jésus, Paris, Éditions du Seuil, 1960, $187 \mathrm{p}$.

+ [S. a.], Histoire du père La Chaize, jésuite et confesseur du roi Louis XIV, où l'on verra les intrigues secrettes qu'il a eues à la cour de France et dans toutes les cours d'Europe [...]. Ses amours avec plusieurs dames de la première qualité, et les agréables aventures qui lui sont arrivées dans le cours de ses galanteries, $2^{\mathrm{e}}$ partie, Bruxelles, Henry Kistemaechers, 1894, 276 p.

+ HUDON, L[éonidas], Vie de la mère Marie-Catherine de Saint-Augustin, $2^{\mathrm{e}}$ édition, Paris, Spes, 1925, $268 \mathrm{p}$.

+ [S. a.], Le père Lacombe: «l'homme au bon cœur». D'après ses mémoires et souvenirs recueillis par une sœur de la Providence, Montréal, Imprimerie du Devoir, 1916, 547 p.

+ [S. a.], Les Jésuites en Chine (1552-1773). La querelle des rites présentée par Étiemble, Paris, Julliard, coll. "Archives», 1966, 301 p.

+ MABILLE, Pierre, Thérèse de Lisieux, Saint-Armand, Denoël-Gonthier, coll. «Médiations», 1978, $116 \mathrm{p}$.

+ MARIE GABRIELLE (sœur), Parfum d'ombre. Vie de sœur Marie Zoé, religieuse de Saint-Joseph de Saint-Vallier, Québec, L'Action catholique, 1943, 202 p. 
+ MARTIN, F., Autobiographie du père Chaumonot de la Cie de Jésus, Paris, H. Oudin, 1885, 291 p.

+ [S. a.], Mère Marie du Sacré-Cour (1806-1885), fondatrice du Bon-Pasteur de Québec, et ses collaboratrices; par une religieuse du même institut, Québec, Asile du Bon-Pasteur, 1935, 276 p.

+ MILICENT, Roses de joie, de souffrance et de gloire, Trois-Rivières, Imprimerie Saint-Joseph, 1943, $86 \mathrm{p}$.

+ MITCHELL, Estelle, Mère Jane Slocombe, neuvième supérieure générale des Sours grises de Montréal, 1811-1872, Montréal, Fides, 1964, 494 p.

+ MONGOLFIER, Étienne, La vie de la vénérable sœur Marguerite Bourgeois, dite du SaintSacrement... Tirée de mémoires certains, et la plupart originaux, Villemarie [Montréal], 1818, $270 \mathrm{p}$.

+ [S. a.], Monseigneur de Saint-Vallier, sa vie, abrégée par une ursuline des Trois-Rivières [Mère Marie-de-la-Nativité], avec une lettre d'approbation de $\mathrm{M}^{\mathrm{gr}}$ Cloutier, et une introduction de N[apoléon] Caron, Trois-Rivières, R.P. Dupont imprimeur-éditeur, 1914, 114 p.

+ MONTGUERRE, Jean-Marc, François-Xavier dans les chemins de l'Orient, Paris, France Empire, 1961, $238 \mathrm{p}$.

+ MOORE, Thomas, Voyage d'un jeune Irlandais à la recherche d'une religion, avec des notes et des éclaircissements, traduit par l'abbé Didon, troisième édition, Paris, Gaume et frères, 1836, 427 p.

+ MULLAHY, Bernard, La spiritualité du très révérend père Basile Antoine Moreau, traduit de l'anglais par le R.P. Albert Monplaisir, [s. v.], tiré à part de L'Écho de Sainte-Croix, 1950, 90 p.

+ NAGOT, François-Charles, Vie de M. Olier, curé de S. Sulpice, à Paris; fondateur et premier supérieur du séminaire du même nom, Versailles, imprimerie J. A. Lebel, 1818, 646 p.

+ NERCAM, André, Vie d'Adèle Coulombe, religieuse hospitalière de l'hôtel-Dieu de Montréal en Canada, Tours, Mame, 1863, 267 p.

+ [S. a.], Notice sur la révérende mère Marie de la Providence, fondatrice de la Société des religieuses auxiliatrices des âmes du Purgatoire, 5e édition, Paris, Librairie Victor Lecoffre, 1907, 301 p.

+ OLIVIER, Marie-Joseph, Un curé breton au $19^{e}$ siècle. Vie de $M^{g r} H u c h e t$, archiprêtre de la cathédrale de Saint-Malo, vicaire général de Rennes, deuxième édition, Paris, Imprimerie et librairie centrale des chemins de fer, 1888, $311 \mathrm{p}$.

+ PAMPALON, Pierre, Une fleur canadienne dans l'Institut Saint-Alphonse ou Notice biographique du serviteur de Dieu, le R.P. Pampalon, Montréal, École catholique des sourds et muets, 1907, 163 p.

+ POIRIER, Pascal, Le père Lefebvre et l'Acadie, troisième édition, Montréal, Beauchemin, 1898, $311 \mathrm{p}$.

+ PONET, Bordeaux Marthe, Catherine de Longpré (au Canada, une héroïque missionnaire de seize ans), Paris, Grasset, 1957, 228 p.

+ PONSONAITHE, Charles, Vie des saints, Tours, Mame et fils, [s. d.], 399 p.

+ RASTIBONNE, Marie Théodore, Histoire de saint Bernard, deuxième édition, revue et augmentée, Paris, Librairie catholique Périsse et frères, 1843, 2 vol.

+ REGOURD, Louis, Notice sur la vie et la mort de M. Mich. F. H. Prévost, prêtre du séminaire de St-Sulpice, curé d'office de Montréal, Montréal, E. Sénécal, 1864, 126 p.

+ RIGAULT, Georges, Histoire générale de l'Institut des frères des écoles chrétiennes, t. IX: La fin du $19^{e}$ siècle, Paris, Plon, 1953, 402 p.

+ ROUVIER, Frédéric, Les bienheureux martyrs de la $C^{i e}$ de Jésus au Canada, Montréal, Le messager canadien, 1925, $33 \mathrm{p}$.

+ SAINT-PAUL, François de, Jean de Matha, un fondateur d'avant garde, Paris, Arthème Fayard, coll. «Bibliothèque Ecclesia», 1960, 168 p. 
+ SAINTE-MARIE, François de, Initiation à saint Jean-de-la-Croix, Paris, Éditions du Seuil, 1946, $208 \mathrm{p}$.

+ TÉTU, Henri, Son Éminence le cardinal Taschereau, archevêque de Québec, Québec, N. S. Hardy, $1891,117 \mathrm{p}$.

+ THÉRIO, Adrien, Ignace Bourget, écrivain, Montréal, Éditions Junonville, 1975, 195 p.

+ TREMBLAY, Pierre, Une âme canadienne extraordinairement ordinaire: Marie Claire Tremblay, 1916-1939, Ottawa, Éditions du lévrier, [s. d.], 375 p.

+ TRUDEL, Paul Eugène, Le serviteur de Dieu, père Frédéric de Guyvelde et de Bethléem, TroisRivières, Éditions BPF, 1947, 337 p.

+ UN AMI [DOHERTY, Patrick], L'abbé Doherty: ses principaux écrits en français, précédés d'un portrait et d'une notice biographique, avant-propos du père L. H., Québec, Augustin Côté et Cie, $1872,126 \mathrm{p}$.

+ [S. a.], Une âme d'élite: Gérard Raymond, 1912-1932, Québec, Séminaire de Québec, 1933, $113 \mathrm{p}$.

+ [S. a.], Une fondatrice et son œuvre: mère Mallet, 1805-1871, et l'Institut des Sours de la charité de Québec, fondé en 1849, Québec, Maison mère des Sœurs de la charité, 1939, 622 p.

+ [S. a.], Une mystique canadienne: mère Catherine-Aurélie du Précieux-Sang; son œuvre, ses vertus, Trois-Rivières, Monastère du Précieux-Sang de Trois-Rivières, 1935, 130 p.

+ UNE RELIGIEUSE DU BON-PASTEUR [Marie de St-Edmond], Sous les feux des Saints-Cours. Le Bon-Pasteur à Sainte Darie, 1870-1920, Montréal, Beauchemin, 1937, 244 p.

+ VALLÉE, Henri, M. l'abbé F.-X. Noiseux, curé des Trois-Rivières, 1796-1812, Trois-Rivières, père H. Marineau, 1931, $54 \mathrm{p}$.

+ [S. a.], Vie admirable du chanoine Joseph-Onésime Brousseau, fondateur de la congrégation des Soeurs de N.-D. du Perpétuel-Secours de Saint-Damien (Bellechasse), Québec, L'Action sociale, 1929, $197 \mathrm{p}$.

+ [S. a.], Vie de $\mathrm{M}^{\mathrm{gr}}$ Cook, $1^{\text {er }}$ évêque de Trois-Rivières, Montréal, Imprimerie A. P. Pigeon, 1898, $224 \mathrm{p}$.

+ [S. a.], Vies de Jérome le Royer de la Dauversière et de mère Marie de la Ferre, fondateurs de I'Institut des religieuses hospitalières de Saint-Joseph, Nîmes, Éditions Notre-Dame, 1936, 143 p.

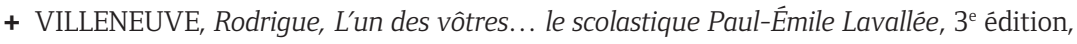
Montréal, Fides, 1945, 285 p.

\section{COMMUNAUTÉS ET ORDRES RELIGIEUX}

+ ARNOULD, Auguste Jean-François, Les Jésuites depuis leurs origines jusqu'à nos jours. Histoire, types, mœurs, mystères, Paris, Dutertre éditeur, 1846, 565 p.

+ BAUMIER, J.-C. (chanoine), L'Union romaine des Ursulines, Trois-Rivières, Année Sainte, 1951, $100 \mathrm{p}$.

+ BERNARD, Antoine, Les clercs de Saint-Viateur au Canada (le 1r demi-siècle: 1849 à 1870), Montréal, Les clercs de Saint-Viateur, 1947, 650 p.

+ BRESCIANI, Antonio, L'épopée des zouaves pontificaux, Paris, Casterman, [s. d.], 290 p.

+ BRESSANY, F[rancesco] G[iuseppe], Relation abrégée de quelques missions des pères de la $C^{\text {ie }}$ de Jésus dans la Nouvelle-France, Montréal, des presses à vapeur de John Lovell, 1852, 336 p.

+ CASGRAIN, Henri Raymond (abbé), Les sulpiciens et les prêtres des missions étrangères en Acadie, 1676-1762, Québec, Pruneau et Kirouac, 1897, 459 p.

+ CERBElAUC-SAlAGNAD, Georges, Les zouaves pontificaux, Paris, France Empire, 1963, 358 p. 
+ COLLIN DE PLANCY, Jacques-Albin-Simon, Les Jésuites: entretiens des vivants et des morts. À la frontière des deux mondes, quatrième édition, Paris, Saynier et Bray, 1853, 263 p.

+ DIONNE, N[arcisse]-E[uthrope], Serviteurs et servantes de Dieu en Canada, Québec, [s. é.], 1904, $318 \mathrm{p}$.

+ DROLET, Gustave A., Zouaviana, étape de trente ans: 1868-1898, Montréal, Eusèbe Sénécal et $\mathrm{C}^{\mathrm{ie}}, 1898,605 \mathrm{p}$.

+ FRANCOEUR, A[thanase], Nos zouaves et la Sainte Vierge, Québec, [s. é.], 1924, 132 p.

+ GARNIER, Adrien, La pieuse union du trépas de Saint-Joseph, [s. v.], Ateliers d'imprimerie de l'Action catholique, 1934, $241 \mathrm{p}$.

+ LAFORTUNE, Édouard, Canadiens en Chine. Croquis du Su-Tchéou Fou, mission des Jésuites du Canada, Montréal, L'Action paroissiale, 1930, 230 p.

+ [S. a.], Les Ursulines de Trois-Rivières depuis leur établissement jusqu'à nos jours, Trois-Rivières, père V. Ayotte, 1888, 4 vol.

+ MARIE-ANTOINETTE (mère), Histoire des Filles de la charité, servantes de pauvres dites Sœurs de la Providence. Préliminaires et fondation, 1800-1844, Montréal, Maison mère des Sœurs de la Providence, 1928, 6 vol.

+ MARIE MICHEL ARCHANGE (sœur), Par ce signe, tu vivras. Histoire de la congrégation des Petites Franciscaines de Marie, 1889-1955, deuxième édition, Baie-Saint-Paul, [s. é.], 1956, $539 \mathrm{p}$.

+ MICHELET, Jules et Edgar QUINET, Des Jésuites, Paris, Jean-Jacques Pauvert, 1966, 260 p.

+ PICOT, Joseph, La seigneurie de l'abbaye de l'île Barbe, Lyon, J. Desvigne, 1953, 115 p.

+ RECALDE, Ignace de, Les Jésuites sous Aquaviva: la canonisation de saint Ignace; la compagnie et les illuminés d'Espagne; condamnation de Suarez; la crise du généralat; imago primi saeculi, d'après des documents inédits extraits des archives du Vatican, Paris, Librairie moderne, 1927, $306 \mathrm{p}$.

+ SÉGUIN, Robert-Lionel, La sorcellerie au Canada français, Montréal, Ducharme, 1961, 188 p.

\section{PAROISSES ET INSTITUTIONS}

+ ALLAIRE, J[ean]-B[aptiste]-A[rthur], Histoire de la paroisse de Saint-Denis-sur-Richelieu, SaintHyacinthe, Imprimerie du courrier de Saint-Hyacinthe, 1905, 543 p.

+ BAILlARGEON, Noël, Le séminaire de Québec de 1685 à 1760, Québec, Presses de l'Université Laval, 1977, $459 \mathrm{p}$.

+ CASGRAIN, H[enri]-R[aymond] (abbé), Histoire de l'hôtel-Dieu de Québec, Québec, Léger Brousseau, 1878, $611 \mathrm{p}$.

+ CASGRAIN, René É[douard], Histoire de la paroisse de L'Ange-Gardien, Québec, Dussault et Proulx imprimeurs, 1902, 373 p.

+ CHAMBERLAND, Michel, Histoire de Notre-Dame-des-sept-douleurs de Grenville, P.Q., Montréal, Imprimerie des sourds et muets, 1931, 310 p.

+ CHOQUETTE, C[harles] P[hilippe], Histoire du séminaire de Saint-Hyacinthe, Montréal, Imprimerie des sourds et muets, 1911-1912, 2 vol.

+ D’ALLAIRE, Micheline, L'Hôpital général de Québec, Montréal, Fides, 1971, 251 p.

+ DAVID, L[aurent]-O[livier], Le clergé canadien: sa mission, son œuvre, Montréal, [s. é.], 1896, $123 \mathrm{p}$.

+ DEMERS, Benj[amin], La paroisse de Saint-Romuald avant et depuis son érection, Québec, J. A. K. Laflamme, 1906, 394 p. 
+ MORIN (sœur), Annales de l'hôtel-Dieu de Montréal, Montréal, Imprimerie des éditeurs ltée, 1921, $252 \mathrm{p}$.

+ PERRIN, Julien, La chapelle de Notre-Dame-de-Lourdes, Montréal, Fides, 1954, 40 p.

\section{A R T RELIGIEUX}

+ BARBEAU, Marius, Trésors des anciens Jésuites, Ottawa, Musée national du Canada, 1957, $242 \mathrm{p}$.

+ BRÉHIER, Louis, Les origines du crucifix dans l'art religieux, Paris, Bloud et Cie, 1908, coll. «Art et littérature», 1908, $62 \mathrm{p}$.

+ [S. a.], La danse des morts comme elle est dépeinte dans la louable et célèbre ville de Basle, deuxième édition, Paris, Maison de la Bonne Presse, [s. d.], 81 p.

+ MARRAUD, Léonce, Imagerie religieuse et art populaire, Paris, Imprimerie F. Paillart, 1913, 39 p.

+ NOPPEN, Luc, Les églises de Charlesbourg et l'architecture religieuse au Québec, Québec, Ministère des Affaires culturelles, 1972, 132 p.

+ PORTER, John, Calvaires et croix de chemin du Québec, Montréal, Hurtubise, 1973, 256 p.

+ ROY, Pierre-Georges, Les cimetières de Québec, Lévis, [s. é.], 1941, 270 p.

\section{MÉLANGES, LITTÉRATURE, ESSAIS ET RÉCITS}

+ ARRAGAIN, Jacques, Le cœur du seigneur, Paris, Éditions du Vieux-Colombier, 1955, 203 p.

+ BAETEMAN, J[oseph], Plus près de toi, mon Dieu, Evreux, G. Poussin, 1939, 252 p.

+ BENDA, Julien, L'Ordination, Paris, Larousse, [s. d.], 154 p.

+ BERNIER, Robert, La roue et la croix, Montréal, Éditions Bellarmin, coll. «Ma paroisse», 1953, $45 \mathrm{p}$.

+ BRÉMOND, Henri, La littérature religieuse d'avant-hier et d'aujourd'hui. À propos de la nouvelle collection «La pensée chrétienne», Paris, Bloud et Cie, 1908, 155 p.

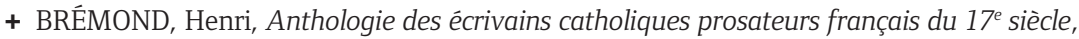
recueillis et publiés par Henri Brémond et Charles Groleau, Paris, Éditions Georges Cres, 1919, $448 \mathrm{p}$.

+ BRÉMOND, Henri, Le roman et l'histoire d'une conversion, Paris, Plon, 1925, 263 p.

+ BRÉMOND, Henri, Autour de l'humanisme, d'Érasme à Pascal, Paris, Grasset, 1937, 299 p.

+ BRÉMOND, Henri, Histoire du sentiment religieux en France depuis la fin des guerres de religion jusqu'à nos jours, Paris, Armand Colin, 1967, 11 vol.

+ CHAIGNE, Louis, Anthologie de la renaissance catholique, t. II, Paris, Alsatia, [s. d.], 297 p.

+ CLAUDEL, Paul, Un poète regarde la croix, seizième édition, Paris, Gallimard, 1935, 188 p.

+ COCHOIS, Paul, Bérulle et l'école française, Bourges, Éditions du Seuil, 1963, 191 p.

+ COLLIN DE PLANCY, Jacques-Albin-Simon, Dictionnaire infernal, Paris, Club du libraire, 1963, $333 \mathrm{p}$.

+ DE LAMIRANDE, Émilien, Études sur l'ecclésiologie de saint Augustin, Ottawa, Éditions de l'Université d'Ottawa, 1969, 206 p.

+ DELTEIL, Joseph, Jésus II (roman), Paris, Flammarion, 1947, 223 p.

+ DICKENS, Charles, La vie de N.S. Jésus-Christ, Paris, Gallimard, 1934, 127 p.

+ GOSSELIN, Auguste, Au pays de M ${ }^{g r}$ Laval. Lettres de voyage, Québec, Laflamme et Proulx, 1910, $351 \mathrm{p}$.

+ GUILLON, Jean, Génie de Pascal, Paris, Aubier, 1962, 182 p.

+ HOCÉYNE-AZAD, L'aube de l'espérance, Paris, E. Guilmoto, 1909, 283 p. 
+ LASERRE, Pierre, La jeunesse d'Ernest Renan, histoire de la crise religieuse au XIXe siècle, t. I, Paris, Garnier, 1925, $370 \mathrm{p}$.

+ LE BRETON, Grandmaison, Pierre Nicole, Paris, Albin Michel, 1945, 197 p.

+ LUCAS, Joseph, Mystère au seuil du paradis, Paris, Alsatia, 1939, 115 p.

+ MARROU, Henri Irénée, Saint Augustin et l'augustinisme, Bourges, Éditions du Seuil, 1955, $191 \mathrm{p}$.

+ ORCIBAL, Jean, Saint Cyran et le jansénisme, Bourges, Éditions du Seuil, 1961, 190 p.

+ OZANAM, Antoine-Frédéric, Euvres complètes, t. V: Les poètes franciscains en Italie au XIII ${ }^{e}$ siècle, avec un choix de petites fleurs de Saint-François, quatrième édition, Paris, Librairie Jacques Lecoffre, 1872.

+ PASCAL, Blaise, Les provinciales, Paris, Fasquelle, [s. d.], 444 p.

+ PASCAL, Blaise, Lettres et opuscules, Lausanne, Guilde du livre, 1958, 321 p.

+ POULAILlE, Henry, La grande et belle bible des noëls anciens, Paris, Albin Michel, 1951, 538 p.

+ [S. a.], Relations de Jésuites contenant ce qui s'est passé de plus remarquable dans les missions des pères de la $C^{i e}$ de Jésus dans la Nouvelle-France, Québec, Augustin Côté, 1858, 3 vol.

+ ROY, Raoul, Jésus, guerrier de l'indépendance, Montréal, Parti pris, 1975, 414 p.

+ SAINT CHARLES GARNIER, Lettres de saint Charles Garnier à son frère, le père Henri de SaintJoseph, Québec, [s. é.], 1931, 45 p.

+ TURPIN, François Henri, La France illustre ou le Plutarque français. Contenant les éloges historiques des généraux \& grands capitaines; des ministres d'État \& des principaux magistrats de la Nation française, t. VIII : Histoire ou Éloge du cardinal de Richelieu, [s. v.], Imprimerie Valleyre aîné, [s. d.], 82 p.

+ UN FRÈRE MARISTE, Histoires canadiennes pour catéchismes, t. I: I-Saint-Joseph; II-Saint Anne; III-Charité; IV-Sacrements, Montréal, Bibliothèque de l'Action Française, 1927, 246 p.

+ VEUILLOT, Louis, Molière et Bourdaloue, Paris, Société générale de librairie catholique, 1877, $269 \mathrm{p}$.

+ [VILLENEUVE, Alphonse], La comédie infernale ou Conjuration infernale aux enfers par un illuminé, Montréal, Imprimerie du Franc Parleur, 1852, 314 p.

\section{S CIENCES HUMA I NES}

+ ALAIN, Propos sur le christianisme, Paris, Frieder et Cie, 1924, 174 p.

+ ALAIN, Les dieux, Paris, Gallimard, 1952, 250 p.

+ ALAIN, Les arts et les dieux, préface d'André Bridoux, texte établi et présenté par Georges Beneze, Paris, Gallimard, coll. «La Pléiade», 1961, 1442 p.

+ CAILLOIS, Roger, L’homme et le sacré, Paris, Gallimard, coll. «Idées. NRF», 1963, 238 p.

+ CHAMBERLAIN, Howard, La signification historique du christianisme, Paris, Librairie L. Rodstein, 1935, 28 p.

+ CLÉMENT, Marcel, Introduction à la doctrine sociale catholique, Montréal, Fides, 1951, 187 p.

+ DURKHEIM, Émile, Les formules élémentaires de la vie religieuse, quatrième édition, Paris, Presses universitaires de France, 1960, 647 p.

+ FIESEINGER, Charles, Erreurs sociales et maladies morales, Paris, Perrin, 1909, 372 p.

+ GOURSAT, Léopold, Les mystères sataniques de Lourdes à travers les âges, Paris, Arthur Savaete, 1905, $123 \mathrm{p}$.

+ MOREUX, Colette, Fin d'une religion? Monographie d'une paroisse canadienne-française, Montréal, Presses de l'Université de Montréal, 1969, 485 p. 
+ MULLER, Max, Essais sur l'histoire des religions, Paris, Librairie académique Didier, 1872, 526 p.

+ ROSTENNE, Paul, La foi des athées, Paris, Plon, 1953, 245 p.

+ RUSSELL, Bertrand, Pourquoi je ne suis pas chrétien, Utrecht, Jean-Jacques Pauvert, 1964, $177 \mathrm{p}$.

+ THIOLLIER, Marguerite Marie, Dictionnaire des religions, Paris, Larousse, 1966, 255 p. 